\title{
A Content Management System (CMS) for a North-South's Research Network
}

\author{
Emilie Gentilini, Aurélie Gandour, and Amanda Regolini \\ Cemagref, St Martin d'Hères, France
}

\author{
Emilie.Gentilini@cemagref.fr Aurelie.Gandour@cemagref.fr \\ Amanda.Regolini@cemagref.fr
}

\begin{abstract}
FragforNET is a North-South network platform to communicate, disseminate and archive information and knowledge on forest fragmentation and biodiversity loss http://fragfornet.grenoble.cemagref.fr/. This network intends to become a portal for researchers, stakeholders, policy makers and the public to exchange ideas, knowledge, data, experiences and results on the loss on biodiversity in the remaining native forests of South America. The activities in relation to the spread of information and access to documentation focus on two main aspects: development of information access and communication tools and enhancement of the identification of Documentary Centre's and specialised libraries by the creation of a common directory. Actions are being done to contribute to an information portal in relation to forest conservation.
\end{abstract}

Keywords: Experts network, native forests, forest fragmentation, South America; biodiversity conservation; CBD 2010, information, communication, platform, North-South experts, Library information Network, open-access, conservation ethic.

\section{Introduction}

FragForNet is a research and information exchange network for a community working on forest conservation issues. FragForNet also serves as a network's communication platform. The network aims to provide reliable and fast information to the community working on native forest fragmentation.

The main needs that were identified behind the network are based on communication and exchange together with the need to overcome the lacks in documentation access. The network also serves to link researchers and decision makers on issues related to conservation and management. This network does not receive any financial support and is maintained on voluntary bases from a truly bottom up approach under the interests of users, information professionals and researchers.

Material published as part of this publication, either on-line or in print, is copyrighted by the Informing Science Institute. Permission to make digital or paper copy of part or all of these works for personal or classroom use is granted without fee provided that the copies are not made or distributed for profit or commercial advantage AND that copies 1) bear this notice in full and 2) give the full citation on the first page. It is permissible to abstract these works so long as credit is given. To copy in all other cases or to republish or to post on a server or to redistribute to lists requires specific permission and payment of a fee. Contact 0HPublisher@InformingScience.org to request redistribution permission.
The inspirational ideas behind this network are found on the framework of the "Paris Declaration for the biodiversity" (Paris Conference, January 2005). As the Declaration states, we aim at bringing researchers together from developing countries and reinforcing the links between the North and South in order to work towards an improved protection of forest biodiversity in particular. 
The overall goal of creating a network of experts working more precisely on forest fragmentation, biodiversity loss and conservation issues target three main issues:

1. Improving the knowledge and the relevance of the indicators that can be developed and used in relation to forest biodiversity loss in native forests.

2. Facilitating building capacity not only in monitoring and evaluating forest fragmentation but also on forest restoration to mitigate the existing trends on biodiversity loss.

3. At this stage we focus on the South American region, but we would like to see this effort expand to other key regions where native forests still persists.

Our aim is to work on native forest that has a particular important biodiversity value and that has been neglected up to date within the International arena. It is only with a proactive co-operation North-South that we will be able to reach the targets set up by the CBD 2010 (EC, 2001a, 2001b; UN/ECE, 2003) and reinforced during the Biodiversity Conference in Paris (January 2005).

An information portal was launched to share and disseminate information. This portal is based on a CMS technology, Zope Plone. In this paper, through the description of this tool, we show how a CMS suits FragForNet in terms of communication and sharing tool, and more generally on how technologies like Web 2.0 can serve as a tactical plan to improve the dissemination of research results and give greater visibility to scientific publications. We also present limitations of this work.

\section{Network Members}

The network, build up on voluntary bases, at present is composed by 42 organisations and research institutes from 17 countries. It comprises experts and researchers from: 15 universities, 4 public institutions, 2 NGO's, a National park and 2 Forest secretaries at the Ministerial level, and 15 specialised libraries and documentary services. Countries that participate up to date are: Argentina, Austria, Brazil, Bolivia, Canada, Chile, Costa Rica, Denmark, Deutschland, France, Japan, New Zealand, Paraguay, Pakistan, United States, and United Kingdom.

\section{FragForNet Information Network}

The information network aims to enhance the relationship between North-South information professionals working in biodiversity conservation and sustainable development. We would like to improve solutions to help librarians and researchers in this area to work together.

Information has a significant role in sustainable development. The methods for handling information including collection, storage, organization, access and use of data are the basics for action on the Agenda 21, chapter 40 and in the principles of the Rio Summit. Moreover information is a tool for sustainable development (Habib \& Baltz, 2008).

FragForNet librarian's group is advocated to provide support on information systems and documentation. The activities of this support group focus on: i) development of communication tools, ii) facilitation of information access and iii) enhancement of the identification of documentary centres and specialised libraries by the creation of a common directory. Librarians within the network, organise the access to knowledge. They target the specific resources for users needs within the network.

The activities in relation to the spread of information focus on the development of a portal. The platform is a tool to archive and to retrieve information in their research's field, but this portal should also be a communication media for different actors and decision-makers in forest fragmentation and biodiversity loss. These actors should easily find the experts that will contribute to answer their queries. 


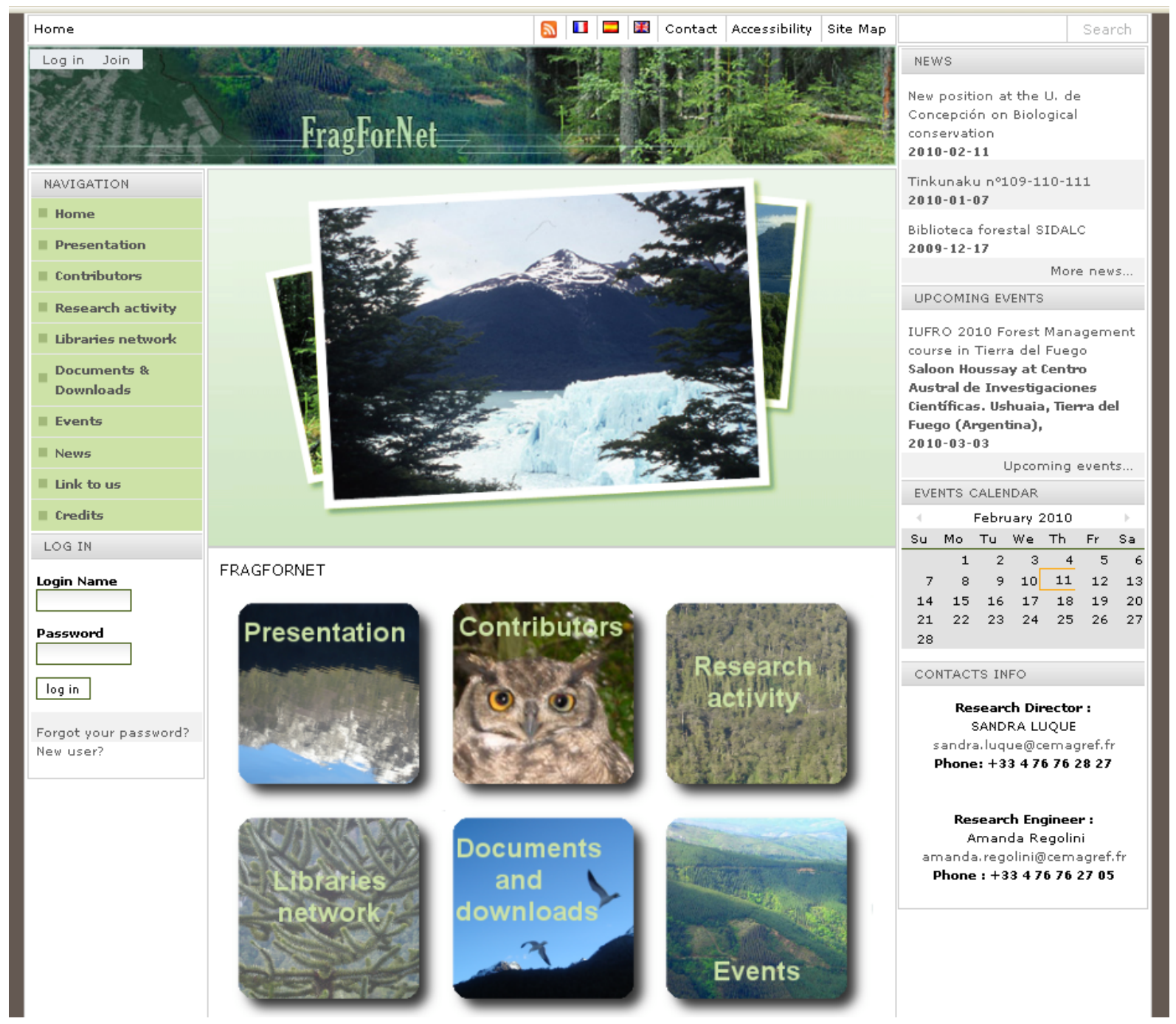

Fig. 1. Opening view of the FragForNet portal (as on 5 February 2010)

\section{Communication Tool: CMS Zope Plone}

\section{Why Zope Plone?}

FragForNet's website is structured by a Content Management System (CMS). A CMS supports creation, management, distribution, publishing and discovery of information. It covers the complete life cycle of the pages on one site, from providing a simple tool to create contents, through publishing, and finally to archiving (Robertson, 2003).

Here, the CMS used is named Plone. This software has been released under the GNU General Public License (GPL). It is built on top of the Zope application server, which is written in Python. All information is stored in Zope's built-in database. It has a friendly interface, a WISIWYG editor and a search engine.

The Plone project began in 1999. The creators were Alan Runyan, Alexander Limi and Vidar Andersen. Very quickly it became one of the most popular CMS. In 2004, a Plone foundation was created to promote the use of Plone. 
One of the CMS asserts is the easy setting of publishing workflows. This system allows the building of workflows so that some contents are accessible by anonymous users, while other contents are only accessible by "logged in" users, and other contents are only accessible for members of a group.

It is possible for a logged user to add or modify content within folders. Moreover the administrator can setup several groups each having access to different sets of private folders.

Another main point is that Plone allows the building of a multilingual website: all of FragForNet's pages are translated in English, French and Spanish.

Ultimately, Plone was chosen because it was the same tool used to develop the websites in Cemagref, our institution. Therefore, it was possible to obtain technical advice and support when needed.

Zope - Plone is also very well implanted in South-America (see:

http://plone.org/countries/conosur), where it has a strong community of users. For example, a South America Plone Symposium is held each year. Moreover, the PloneGov, a cooperation project for e-government initiatives in Latin America, won the biggest French award for open source projects called "Grand prix du jury des Lutèce d'Or" in 2007.

\section{Contents}

Fragfornet's communication tools consist of an e-mail moderated list to exchange information and a website containing users' folders to enter local information and a portal section offering content to the different types of users. The moderated mailing list and the portal are the two main tools to promote information.

The mailing list was built two months after the first meeting in Argentina, in 2006. Through the CMS registration, the members are registered in this e-mail list server. Members receive information on upcoming events related to the aims of the network. Everybody is invited to promote scientific or stakeholders events and related publications. This way the list server allows the community to keep up with news about the latest publications, software's, events and also job openings and projects funding opportunities.

The website was published on February 2008. The logged-in members can access their personal folder on the Website. Using only a web browser, they can store data on it, making it possible to the editors to publish it on the main portal, often as news. Nowadays, member's folders are used to update the website as an intermediate step.

In order to facilitate the access to the information within, the portal's content has been divided into several sections. On the website's homepage, they are represented by two rows of illustrated icons. On all pages of the website, they are accessible through a menu located on the left of the screen.

The presentation and contributors' sections introduce the network and the people supporting it. The research activity and libraries network's sections offer information on the actions of the network. The documents and downloads' section allows the users to access information on forest fragmentation. Last but not least, the news and events' sections promote the latest publications or upcoming events in the field. To enable an instantaneous access to those regularly updated news, those two last sections are accessible through RSS feeds.

Within all of those sections some information is only accessible to the members while the rest is readable by all anonymous users. All this content is translated in English, Spanish and French.

With the goal of making this website (and the whole network along) more visible, a Search Engine Optimization (SEO) of the site has been initiated. The ultimate goal is to push the FragFor- 
Net's pages up on the results' pages of the most used search engines when asked about some preselected keywords.

Those keywords have been chosen given the number of requests and the number or results for each, in the three languages of the site. They then have been carefully inserted in key parts of the site, in order to induce a better indexation by the search engines.

\section{FragForNet CMS Member Typology}

There are three typologies of users: coordinators, librarians, researchers and students.

Researchers and students are allowed to contribute to the portal and to share information but it is not the main target. We consider here that this group is the typical user group that benefits from the network.

Librarians' first task is to meet the needs of researchers. According to their main activity, they use and test Web 2.0 technologies in order to find new tools for researchers. They also use the Website to share information. Librarians don't have any problem in contributing directly on the portal, using the CMS tools. These users' files go through a special workflow.

Coordinators are the producers of main information, but they also stimulate the community's participation, asking them to send their needs and information. At the moment, they use an intermediate step to contribute to the portal. They send their information by email to the editors or put their publications in their personal folders. They ask editors to store files or news on the portal. The next step could be to contribute directly by using the CMS tools. It would mean writing directly in the WISIWYG editor and submit their articles to the editors. Training sessions will be needed to reach that step.

\section{Workflows}

For FragForNet, three workflows have been created. Anonymous users can access the published information. Members' users are allowed to add or modify content within their folders; they can ask the editor to publish the information. Editors select the member's items for further publishing. The editors can modify the content of the whole website.

Published items can be displayed to be visible for anonymous users or for members only. All members have access to a restricted intranet area.

Only two editors are allowed within the portal's administration interface.

A special workflow, intended for the library network, allows users to submit and edit files into the news, events and library network sections. To get help, they can consult a "how to" document. One librarian's session training has already taken place in Argentina. 


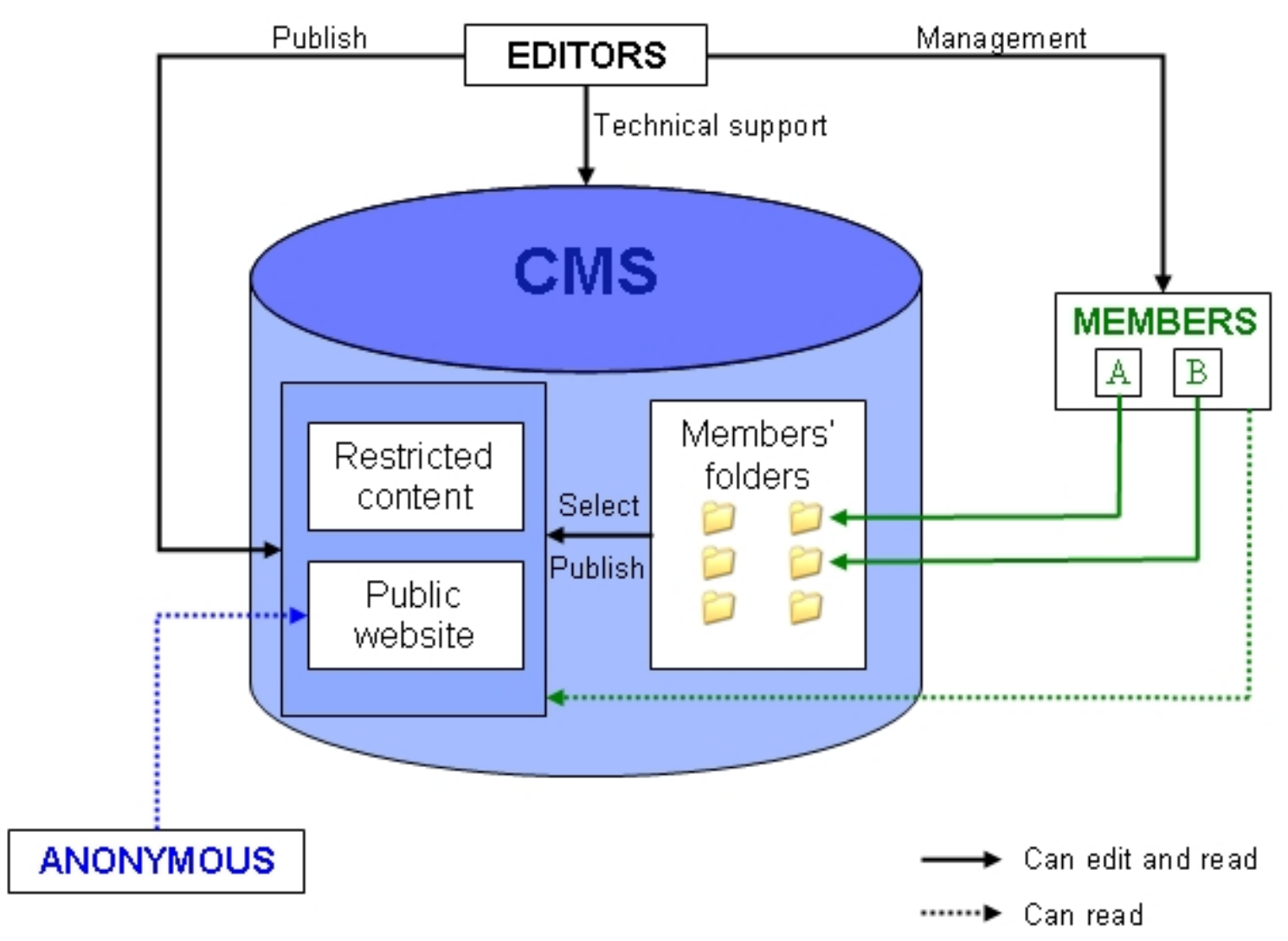

Fig.2: General FragForNet's workflows diagram.

\section{Actual Use of Those Tools}

Members within the network have their own projects published in their laboratory web portals, or personal web pages. Why are they willing to collaborate in this project? It is important to have a look at their scientific communication behaviour. This particular group of researchers knew each other and had already worked together before creating FragForNet. In the typology above, they are named coordinators.

Several studies show that researchers still need to make Web 2.0 technologies their own before using them (Belin, 2003) and sometimes they consider it as an additional and free work (Le Deuff, 2006). Nevertheless, scientific applications of Web 2.0, like scientific weblogs, are increasing (Gallezot, 2009). We can notice that researchers tend to use other sharing tools and volunteer-based information platforms, as Del.icio.us or Wikipedia. These giants are as big as they are because the community they aim at is wide (we're talking about millions of people). In our network, the percentage is slightly the same while the community is smaller. Thereby, only a few researchers in the network store their information on the CMS.

To sum up, coordinators, librarians and researchers are producers of information. Not all of them contribute directly in the CMS, but the main point is that they participate at their own rate. In Wikipedia's community, correction spelling is at least as important as publishing an entire webpage (Salaün, 2009). 


\section{Some Achievements and Results}

After three years of existence, the number of members has increased from 40 to more than 130 .

It is important to point out the workshops already organised by the network: Grenoble, France and Bariloche, Argentina 2006. Under the scientific authority of IALE, International Association of Landscape Ecology: Wageningen, Netherlands, 2007 and Campos de Jordao, Brazil, 2009.

Members of FragForNet have also published a book in the subject on 2007 and one chapter for a Springer's book has been co-authored in 2009.

Some actions of the documentary network are the exchange of experience about different works in progress, especially those helping cope users' needs. We also exchange about different new tools. FragForNet librarians' have already had four working meetings and a workshop at the IALE Conference in Campos de Jordao, Brazil, 2009.

One ongoing project in order to enhance the identification of documentary centres and specialised libraries is a directory for libraries having collections on this subject. The directory is being created; the structure is available in the librarian folder. Each library must complete the information about the services they propose.

In 2009, two actions have been done to improve the information access in collaboration with IUFRO (International Union of Forest Research Organizations) and SIDALC (Sistema de Información y Documentación Agropecuaria de las Américas).

The collaboration with IUFRO is a challenge to promote our information via the Global Forest Information Service (GFIS). FragForNet CMS feeds were linked by the GFIS at www.gfis.net.

SIDALC has achieved a forest portal; it can be consulted at http://orton.catie.ac.cr/mbforestal.htm. Actions have been done to contribute to this information portal about forest conservation. The new forest portal is a result of a query that we made to SIDALC. In order to prepare the references export, FragForNet has provided the thematic word list.

\section{Conclusion}

Two future improvements about FraForNet portal are being studied. The first one could be using it more in a collaborative way. Researchers don't contribute actively to the CMS for the moment. But they use other Web 2.0 tools such as YouTube or Slide Share. One future action will be to encourage contributions. The second one is to improve the portal's visibility. A search engine optimization (SEO) has started in February 2010. Its goal will be to achieve a better ranking of FragForNet within the most used search engines.

The librarian network may collaborate in the following actions: we must know the users' information needs, and for this purpose a survey will be planned. Afterwards, the librarians may find tools and open access services to fulfil those needs. Publishing needs must also be discussed. Indeed, the publishing's costs are high. This way, the network could support his authors into their publishing ambitions.

By cooperating together in a flexible network we intend to develop actions according to the priorities of regional, national and North-South's interests in order to implement an effective information access for experts working in forest biodiversity loss.

\section{Acknowledgements}

We would like to thanks Cemagref and Eric Maldonado for the support on maintaining the network facilities. 


\section{References}

Belin, O. (2003). Un référentiel de connaissances : comment construire un dispositif socio-technique ? Le cas d'une communauté de chercheurs transversale et pluridisciplinaire. Xème Colloque bilatéral franco-roumain, CIFSIC Université de Bucarest, 28 juin-3 juillet 2003.

EC. (2001a). Communication from the Commission to the Council and the European Parliament - Biodiversity Action Plans in the areas of Conservation of Natural Resources, Agriculture, Fisheries, and Development and Economic Co-operation. Brussels. Retrieved October 1, 2004, from http://biodiversitychm.eea.eu.int/convention/cbd_ec/strategy/BAP html

EC. (2001b). Environment 2010: Our future, Our choice - the Sixth Environment Action Programme. $\operatorname{COM}(2001) 31$ final - Brussels.

Gallezot, G., \& Le Deuff, O. (2009). Chercheurs 2.0 ? Les Cahiers du numériques, 5 (2), 15-32.

Habib, A., \& Baltz, C. (2008). Quelle information pour piloter le développement durable? Documentaliste - Sciences de l'information, 45, 4-13

Le Deuff, O. (2008). Le succès du web 2.0 : histoire, techniques et controverses. Retrieved February 4 , 2010, from http://archivesic.ccsd.cnrs.fr/sic 00133571/fr/

Luque, S., Martínez Pastur, G., Echeverría, C., \& Pacha, M. J. (2009). Overview of biodiversity loss in South America: A landscape perspective for sustainable forest management and conservation in temperate forests. In C. Li, R. Lafortezza, \& J. Chen (Eds.), Landscape ecology and forest management: Challenges and solutions in a changing globe. HEP-Springer

Pacha, M. J., Luque, S., Galetto, L., \& Iverson, L. (2007). Understanding biodiversity loss: An overview on forest fragmentation in South America. IALE Landscape Research and Management papers. International Association of Landscape Ecology, 155 p.

Robertson, J. (2003). So, what is a content management system? KM Column. Retrieved October 1, 2009, from http://www.steptwo.com.au/papers/kmc what/index.html

Salaün, J. M., Liziard, D., Mercier, S., et al. (2009). Fondamentaux et usages: Web 2.0 et informationdocumentation: évolution ou révolution ? Documentaliste - Sciences de l'information, 46, 32-43.

UN/ECE. (2003). Declaration by the environment Ministers of the region of the United Nations Economic Commission for Europe (UNECE). Fifth Ministerial Conference "Environment for Europe" Kiev, Ukraine, 21-23 May 2003. ECE/CEP/94/Rev.1. Retrieved October 1, 2004, from http://www.rusrec.ru/homepage/databases/int_law/ece.cep.94.rev.1.e.pdf

\section{Biographies}

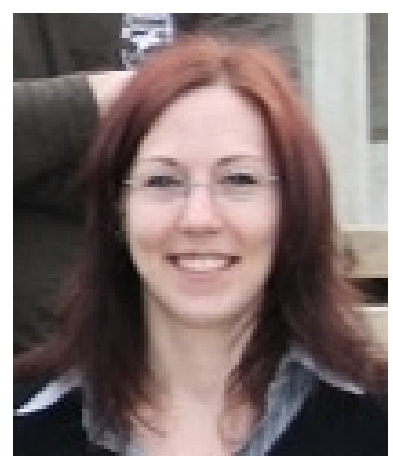

Emilie Gentilini is a 4-year experience information professional in scientific research institutes. She has worked on bibliometric analysis at Cemagref since 2009. 


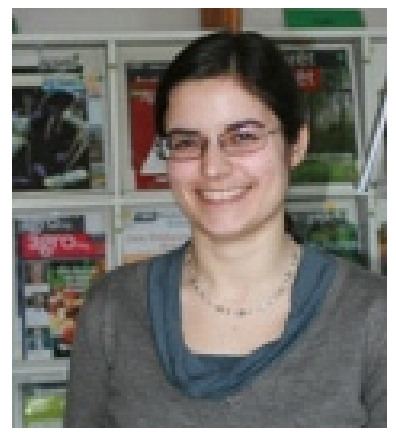

Aurélie Gandour, who recently graduated in Information Sciences, works at Cemagref since 2009. She is the current webmaster of FragForNet's website.

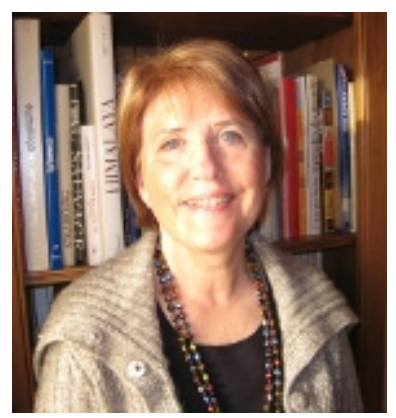

Library director, Amanda Regolini is a research engineer at Cemagref, where she has worked since 1990. She has been responsible for the bibliometric analysis at the institute since 2006. 